Short report

\title{
Erythropoietin levels in posterior fossa haemangioblastoma
}

\author{
RV JEFFREYS, JAF NAPIER, SH REYNOLDS \\ From the Mersey Regional Department of Neurosciences, Walton Hospital, Liverpool, and the \\ Welsh Regional Transfusion Centre, Rhydlafar, St Fagans, Cardiff, UK
}

SUMMARY Using an in vitro bioassay, erythropoiesis stimulating activity has been measured in serum, cyst fluids and tumour homogenates from fourteen patients with cerebellar haemangioblastoma. Only two patients had elevated peripheral blood red cell counts and haemoglobin concentrations. Significantly elevated serum erythropoiesis stimulating activity was found in only one patient. High levels, however, were detected in seven out of the fourteen cyst fluids and in the two homogenates tested. The dose response lines from these paralleled those of normal human erythropoietin. It was possible to neutralise the erythropoiesis stimulating activity in the cyst fluids with anti-human erythropoietin serum, indicating its similarity to erythropoietin, the normal erythropoietic regulating hormone. Significant release of the erythropoietic stimulating factor from the cyst fluids into the blood seemed to be an uncommon occurrence.

The association of posterior fossa haemangioblastoma with increased levels of haemoglobin and red blood cells in the peripheral blood was first described by Carpenter and Walker. ${ }^{1}$ Demonstration of erythropoiesis stimulating activity in the cystic contents ${ }^{2}$ provided insight into the likely mechanism of this association. No increases into the serum activity, however, were found, but this could have been due to the relative insensitivity of the in vivo erythropoietin bioassay then available. More recent reports have confirmed the association between erythrocytosis and the posterior fossa haemangioblastoma. One of the authors (RVJ) reported his findings in a series of sixty-seven parients. $^{3}$ It was found that $18 \%$ of patients presented with erythrocytosis in addition to evidence of a posterior fossa space occupying lesion. This does not explain, however, why $72 \%$ of such patients appear to have normal peripheral red blood cell indices. Recently developed in vitro bioassays for erythropoetin are more sensitive, specific and precise than in vivo assays. Using an in vitro bioassay technique, an attempt has been made to assess the serum and tumour erythropoiesis stimulating

Address for reprint requests: $\mathrm{Mr} \mathrm{RV}$ Jeffreys, Walton Hospital, Rice Lane, Liverpool L9 1AE, UK.

Received 5 September 1981 and in revised form 5 November 1981

Accepted 18 November 1981 activity levels and correlated these with the clinical, pathological and haematological features, in fourteen patients with posterior fossa haemangioblastoma.

\section{Patients, materials and methods}

In the years 1975 to 1979 fourteen patients suffering from posterior fossa haemangioblastoma were admitted to the Mersey Regional Department of Neurosciences, twelve of whom were under the care of RVJ and two others under the care of other neurosurgeons. There were twelve men and two women with an average age of fifty-one (range 25 to 64) years. Since many of these patients required urgent surgery, it was possible to measure the red blood cell mass in one patient only, although peripheral blood counts were performed on all patients. Following neurological investigations, which included CT scanning and vertebral angiography, all patients underwent definitive surgery for the haemangioblastoma by suboccipital craniectomy with either total excision of a solid tumour or drainage of a cystic lesion together with excision of mural nodules. Four patients suffered from the von Hippel-Lindau complex as described by Jeffreys, ${ }^{4}$ three having retinal haemangioblastoma, and two renal carcinoma which led to their ultimate demise. In the other ten patients the haemagioblastoma was solitary with a negative family history. The macroscopic nature of the tumour was defined as cystic (C, table 1$)$ where there was a clear cut cyst with only a mural nodule; part solid and part cystic $(\mathrm{C} / \mathrm{S}$ table 1) or fully solid, (S table 1) in which there were no macroscopic cysts. The haemangioblastoma were graded 
according to the histopathological classification of Silver and Henniger ${ }^{5}$ into three types; Type A-Juvenile, Type B-transitional, and Type C-clear cell.

Serum samples, and in some cases cyst contents or solid tumour fragments, were collected for erythropoietin assay, and stored at $-40^{\circ} \mathrm{C}$ until assayed. After thawing the serum samples, cyst contents and homogenates of the tumour in tissue culture medium were subjected to an acid heat denaturation procedure followed by concentration of the protein depleted supernatant fluid. ${ }^{6}$ Erythropoietin assays on the serum concentrates were formed using a foetal mouse liver cell system modified to use $\mathrm{I}^{\mathbf{1 2 5}}$ deoxyuridine as an indicator of cell proliferation and microtitre culture and harvesting system. ${ }^{6}$ Owing to limitations in the assay sensitivity in the early part of the study, serum erythropoietin results were stated as normal if they could not be shown to be significantly higher than the normal serum pool control.

The neutralisation studies with anti-human erythropoietin were performed using goat anti-human erythropoietin serum (JCL Clinical Research Corporation, Tennessee). Previous titration and characterisation studies had established an approximate neutralising capacity for human erythropoietin at $1000 \mathrm{mu}$ per $\mathrm{ml}$ antiserum but the activity of sheep erythropoietin (Connaught step 3) was largely unaffected.

\section{Results}

The clinical haematological and histological results are shown in table 1 . Only two patients (approximately $18 \%$ ) had a clear cut erythrocytosis with haemoglobin in excess of $18 \mathrm{gms}$ per cent and both had clear cell (Type C) tumour histology. Serum erythropoietin levels were in the normal range (3-32 mu per $\mathrm{ml}$ ) with the sole exception of one of the patients with elevated haemoglobin (case 13) who had $79 \mathrm{mu}$ per ml erythropoietin. Measurement of erythropoiesis stimulating levels in cyst fluids, however, showed extremely high concentrations in seven out of the ten cystic lesions including that of case 13. This was not, however, confined to any of the three cytological types (A, B, or C) and erythro- poiesis stimulating activity was not found in the three remaining cyst samples (two type A, one type C). Comparatively modest amounts of erythropoiesis stimulating activity were present in the solid tumour extracts. The goat anti-human erythrpoietin serum completely abolished the dose response curve of the second WHO International Reference Preparation of erythropoietin, the human serum erythropoietin control and also the cyst fluid erythropoiesis stimulating activity. Radioactive counts were also reduced by anti-erythropoietin serum in the cultures without added erythropoietin which may reflect neutralisation of the erythropoietin in the pooled normal human serum incorporated into the culture medium. Preliminary titration of the anti-erythropoietin serum appeared to reveal a prozone effect with less erythropoietin neutralisation at higher antiserum concentrations. This may have been due to the presence of endogenous erythropoietin in the goat antiserum.

The dose response lines of the second International

Table 2 Effect of goat antihuman erythropoietin serum on erythropoietin and cyst fluid erythropoiesis stimulating activity (ESA)

\begin{tabular}{|c|c|c|}
\hline & $\begin{array}{l}\text { No Anti EP serum } \\
\text { CPM }\end{array}$ & $\begin{array}{l}6 \cdot 25 \mu l \text { Anti EP } \\
C P M\end{array}$ \\
\hline $\begin{array}{l}\text { EP } \\
\text { 2nd International Reference }\end{array}$ & & \\
\hline $\begin{array}{l}\text { Preparations } \\
(3 \mathrm{mu} / 75 \mu \mathrm{l} \text { culture }) \\
\text { EP }\end{array}$ & $8130 \pm 687$ & $272 \pm 111$ \\
\hline $\begin{array}{l}\text { High Potency Human Serum } \\
\text { ( } 3 \mathrm{mu} / 75 \mu \mathrm{l} \text { culture) } \\
\text { Cyst Fluid ESA }\end{array}$ & $8573 \div 1062$ & $366 \pm 237$ \\
\hline $\begin{array}{l}\text { Case } 11 \\
(3 \cdot 2 \mu 1 / 75: \ell 1 \text { culture }) \\
\text { Cyst Fluid ESA }\end{array}$ & $9699 \pm 460$ & $504 \pm 306$ \\
\hline $\begin{array}{l}\text { Case } 13 \\
(3 \cdot 2: 21 / 75 \mu l \text { culture })\end{array}$ & $8589 \div 594$ & $217 \pm 13$ \\
\hline No Added EP & $1158 \pm 254$ & $255 \pm 174$ \\
\hline
\end{tabular}

Results are means of 4 replicates $\pm 1 \mathrm{SD}$.

Table 1 Clinical and laboratory findings in patients with cerebellar haemangioblastoma

\begin{tabular}{|c|c|c|c|c|c|c|c|c|c|c|c|c|c|}
\hline $\begin{array}{l}\text { Case } \\
\text { No }\end{array}$ & $\begin{array}{l}\text { Age } \\
y r\end{array}$ & Sex & $\begin{array}{l}\text { VHL or } \\
\text { not }\end{array}$ & $\begin{array}{l}\text { Solid/ } \\
\text { cyst }\end{array}$ & $\begin{array}{l}\text { Histological } \\
\text { type } A B C\end{array}$ & $\begin{array}{l}H b \\
g / d l\end{array}$ & $\begin{array}{l}H c t \\
\%\end{array}$ & $\begin{array}{l}R B C \\
10^{12}\end{array}$ & $\begin{array}{l}\text { Red } \\
\text { cell } \\
\text { mass }\end{array}$ & $\begin{array}{l}E P \\
\text { serum } \\
\text { mu.ml }\end{array}$ & $\begin{array}{l}\text { EP } \\
\text { tumour } \\
\text { mu.ml }\end{array}$ & $m u / g$ & Outcome \\
\hline 1 & 41 & $\mathbf{M}$ & $\therefore$ & $\mathbf{S}$ & A & 10.4 & 31 & $4 \cdot 5$ & & $\mathbf{N}$ & - & - & $\dagger$ \\
\hline 2 & 63 & $\mathbf{M}$ & - & $\mathbf{S}$ & A & $14 \cdot 5$ & 43 & $4 \cdot 73$ & & $N$ & - & - & $\mathbf{A} / \mathbf{W}$ \\
\hline 3 & 41 & $\mathbf{M}$ & ... & $\mathrm{C}$ & A & $14 \cdot 2$ & 44 & $5 \cdot 16$ & & 28 & 1730 & - & $\dagger$ \\
\hline 4 & 53 & $\mathbf{M}$ & - & $\mathrm{C}$ & A & $14 \cdot 6$ & $41 \cdot 5$ & $4 \cdot 49$ & & 20 & $>1606$ & - & $\mathbf{A} / \mathbf{W}$ \\
\hline 5 & 48 & $\mathrm{~F}$ & - & C & B & $14 \cdot 7$ & 43 & 4.95 & & $N$ & $>8400$ & - & $\mathbf{A} / \mathbf{W}$ \\
\hline 6 & 25 & $\mathbf{M}$ & $\div$ & $\mathrm{S} / \mathrm{C}$ & B & $15 \cdot 5$ & 44 & $5 \cdot 2$ & & $\mathbf{N}$ & $>20000$ & - & $\mathbf{A} / \mathbf{W}$ \\
\hline 7 & 38 & $\mathbf{M}$ & - & $\mathrm{S} / \mathrm{C}$ & B & $16 \cdot 4$ & 46 & $5 \cdot 77$ & & $N$ & 2260 & - & $\mathbf{A} / \mathbf{W}$ \\
\hline 8 & 53 & $\mathbf{M}$ & - & C & B & $15 \cdot 9$ & 47 & $5 \cdot 31$ & & $N$ & 0 & - & $\mathbf{A} / \mathbf{W}$ \\
\hline 9 & 31 & $\mathbf{M}$ & $\therefore$ & C & B & $15 \cdot 7$ & 47 & $5 \cdot 39$ & & 16 & - & - & $\mathbf{A} / \mathbf{W}$ \\
\hline 10 & 39 & $\mathrm{~F}$ & - & $\mathrm{S} / \mathrm{C}$ & B & $15 \cdot 0$ & $44 \cdot 5$ & $4 \cdot 69$ & & 16 & $>3000$ & $127 \cdot 0$ & $\mathbf{A} / \mathbf{W}$ \\
\hline 11 & 61 & M & - & S & C & $15 \cdot 1$ & 46 & 4.99 & $\hat{i}$ & $N$ & - & - & $\dagger$ \\
\hline 12 & 50 & M & + & $S$ & C & $18 \cdot 8$ & 56 & $6 \cdot 51$ & 2701 & $N$ & & $123 \cdot 0$ & $\mathbf{A} / \mathbf{W}$ \\
\hline 13 & 63 & $\mathbf{M}$ & - & $\mathrm{S} / \mathrm{C}$ & C & $18 \cdot 4$ & 55 & $5 \cdot 98$ & & 79 & $>4000$ & - & $\dagger$ \\
\hline 14 & 64 & $\mathbf{M}$ & - & C & C & $14 \cdot 0$ & 42 & $4 \cdot 79$ & & 30 & - & - & $\mathbf{A} / \mathbf{W}$ \\
\hline
\end{tabular}

A/W-alive and well, $\dot{t}$--deceased; VHL_-Von Hippel-Lindau disease; EP-erythropoietin. 
Reference Preparation human serum and cyst fluid erythropoiesis stimulating activity all showed significant parallelism $(\mathrm{p}<0.5)$ when examined by the parallel line bioassay statistical procedure as described by Colquhoun.?

\section{Discussion}

The in vitro bioassay technique used in this study is of sufficient sensitivity to allow valid multiple dose parallel line comparisons during assays of most clinical material. This gives confidence that the erythropoiesis stimulating activity is in fact erythropoietin rather than an erythropoiesis stimulator enhancing endogenous activity. The activity found in cyst content shows a high degree of parallelism with the erythropoietin standard preparations suggesting its pharmacological identity with that hormone. This conclusion is reinforced by the demonstration that the anti-human erythropoietin antisera completely neutralises the in vitro biological activity.

Previous studies $^{8} 9$ showed that haemangioblastoma cyst erythropoietin has similar properties to urinary derived erythropoietin as judged by study of radiation induced inactivation and susceptibility to trypsin and sialidase treatment. These authors also found abolition of erythropoiesis stimulating activity with erythropoietin antisera though the in vivo bioassay used could not differentiate between direct neutralisation of erythropoietin in cyst fluid and neutralisation of erythropoietin formed within the assay animals as a result of cyst fluid injection.

The original suggestion by Jeffreys ${ }^{4}$ that type A tumours appeared only in younger patients is not substantiated in this series where it will be seen that type A tumours occurred in patients ranging from 41 to 63 years of age. The findings for type $B$ and $C$ tumours, however, are much in keeping with the previous series. It is particularly interesting to note that the two patients with erythrocytosis (haemoglobin in excess of $18 \mathrm{~g} / \mathrm{dl}$ ) also suffered from type $\mathrm{C}$ tumours, findings in agreement with Jeffreys. ${ }^{4}$ The erythropoietin levels in the tumour were very high in both these patients though it should be noted that high levels were also seen in patients with blood counts in the normal range and this observation together with the lack of elevation of serum erythropoietin levels suggests that erythropoietin is largely retained within the tumour. The factors determining leakage of sufficient erythropoietin to cause erythrocytosis and elevated serum levels remain to be elucidated. It therefore appears unlikely that measurements of serum erythropoietin would be helpful in assisting the differential diagnosis of posterior fossa neoplasms. Whether following serum erythropoietin measurements or blood counts in the occasional patient with elevations in these parameters provide any guide to relapse remains to be determined. Cerebrospinal fluid levels of erythropoietin were not determined in this study but should be investigated in this context.

The present work was performed with the assisance of a grant from the Welsh Scheme for health and social research and also the Medical Research Council. The authors are grateful to the World Health Organisation for the supply of the 2nd International Reference Preparation of Erythropoietin. Thanks are due to Carol Dawson for technical assistance with the assay.

\section{References}

${ }^{1}$ Carpenter G, Schwartz HG, Walker AE. Neurogenic polycythemia. Ann Internal Medicine 1943;19: 470-1.

${ }^{2}$ Waldmann TA, Levin EH, Baldwin M. The association of polycythemia with cerebellar haemangioblastoma. Am J Med 1961 ;31 :318-24.

${ }^{3}$ Jeffreys RV. Pathological and Haematological Aspects of Posterior Haemangioblastomata. J Neurol Neurosurg Psychiatry 1975;38:112-9.

4 Jeffreys RV. Haemangioblastoma of Neuroxis. M.Chir. thesis (University of Cambridge). 1974.

s Silver ML, Hennigar G. Cerebellar hemaniomia (haemangioblastoma). A clinico-pathological review of 40 cases. $J$ Neurosurgery 1952;9:484-94.

${ }^{6}$ Napier JAF, Evans J. Erythropoietin assay using foetal mouse liver cell cultures: a modified technique using semis-automatic harvesting of ${ }^{125} 1$ deoxyuridine labelled erythroblasts. Clin Lab Haemat 1980;2:13-9.

${ }^{7}$ Colquhoun D. Lectures on Biostatistics. Oxford University Press, London. 1971.

${ }^{8}$ Rosse WF, Berry RJ, Waldmann TA. Some molecular characteristics of erythropoietin from different sources determined by inactivation by ionizing radiation. J Clin Investigation 1963;42:124-9.

${ }^{9}$ Rosse WF, Waldmann TA. A comparison of some physical and chemical properties of erythropoiesisstimulating factors from different sources. Blood 1964;24:739-49. 